\title{
Unpacking the meaning of sense of coherence in transcultural management
}

\begin{abstract}
Book Title:
The meaning of sense of coherence in transcultural management
\end{abstract}

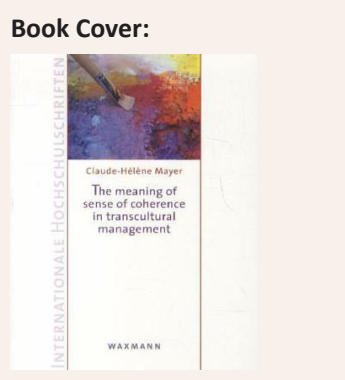

Author:

C. Mayer

ISBN:

978-3830925538

Publisher:

Waxmann Publishing

Company, 2011, 30.00€*

*Book price at time of review

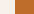

Review Title:

Unpacking the meaning of sense of coherence in

transcultural management

Reviewers:

Llewellyn E. Van Zyl ${ }^{1}$

Marius W. Stander ${ }^{2}$

Affiliations:

${ }^{1}$ Department of Industrial and Organisational Psychology, University of South Africa, South Africa

${ }^{2}$ Department of Industrial Psychology, School for Behavioural Science, NorthWest University, Vaal Triangle Campus, South Africa

Email:

vzylle@unisa.ac.za

Postal address:

3-78 AJH Van Der Walt, University of South Africa, Muckelneuk, 0003, South Africa

Read online:
Dr. Claude-Helene Mayer's new book, titled The meaning of sense of coherence in transcultural management, explores the nuances of managerial stressors and coping mechanisms within the South African business environment. Her unique contribution to the field of human resource management stems from interpreting these nuances from a salutogenetic approach. Antonovsky (1987), the father of this approach, defined salutogenesis as a paradigm centred on human health and the individuals' ability to positively cope with life challenges. In this book, the author aims to examine managers' perceptions of identity, organisational culture, transcultural conflict and sense of coherence from this approach. The focus lays on understanding how managers can increase their ability to activate and optimise internal resources in order to cope with daily work-related demands.

The book follows a doctoral thesis chapter structure, starting with an introduction and orientation, presenting the research context, elaborating on the research design, presenting the findings and ending with conclusions and recommendations. Although each chapter is expertly written and adds value to the field, the layman might find it difficult to navigate their way through the vast amounts of knowledge and insight presented in this book. The book is positioned as a specialist book aimed at academics, researchers and practitioners working in the field of salutogenesis and managerial development. As a specialist book, this work presents interesting insights into understanding the nature of managerial dynamics within the South African context. In essence, the author aims to answer two research questions through mixed method research:

(1) How are sense of coherence, values and identity, transcultural conflict and organisational culture interlinked within the South African business environment?

(2) How could managers be assisted to increase their ability to activate resources and develop a sense of coherence in challenging transcultural organisational settings?

Each chapter is aimed at drawing the reader closer to an answer for the aforementioned research questions. Chapter 1 aims to provide context to the research problem and provide a theoretical overview of the individual and group-related salutogenetic behaviours and the implications associated with managerial functioning. This chapter provides context to the rest of the book as it provides an overview of how the book is structured and which methodology is followed.

Building on the foundation laid in the previous chapter, Chapter 2 succeeds in providing a solid theoretical overview of the South African managerial environment. The author highlights the various struggles that South African businesses are facing (such as BEE compliance, the financial crisis, affirmative action, corporate governance, etc.) with specific reference to the demands being placed on managers. The author's investigation into these aspects presents an interesting context for investigating salutogenetic functioning of managers who have to face these challenges every day.

Chapter 3 and 4 draws from the problems presented in the previous chapter and attempts to provide a theoretical understanding of not only salutogenetic functioning but also of the internal managerial competencies required to manage and cope with the aforementioned work-related demands. Furthermore, the author investigates various strategies implemented by organisations to assist managers to cope with these demands. These strategies include: skills training (such as conflict management, salutogenetic and transcultural training), counselling, coaching, mediation, mentoring and supervision. The author links these interventions to various positive work-related outcomes, such as general health and positive organisational behaviours. She also mentions the practical implications and effectiveness of each strategy within the South African context. Although insightful and practically viable, some of these strategies have been empirically tested within the South African environment, which produced mixed results (Jorgensen, 2009; Spangenberg \& Orpen-Lyall, 2008).

How to cite this book review: Van Zyl, L.E., \& Stander, M.W. (2013). Unpacking the meaning of sense of coherence in transcultural management. SA Journal of Human Resource Management/SA Tydskrif vir Menslikehulpbronbestuur, 11(1), Art. \#543, 2 pages. http:// dx.doi.org/10.4102/sajhrm.v11i1.543

Copyright: ( 2013. The Authors. Licensee: OpenJournals Publishing. This work is licensed under the Creative Commons Attribution License. 
The next chapter is centred on the research design and methodology followed to attempt to answer the research questions. Although not very useful to the practitioner, both academics and researchers may find Chapter 5 interesting. In this chapter, the author describes the research design and methodology followed in this study. The author discusses and presents a solid argument for the use of mixed methods (both quantitative and qualitative) to attempt to understand the internal dynamics of managerial functioning. She describes how a mixed method approach, comprised of indepth interviews and surveys, provides insight into the psyche of the South African manager. For the quantitative methods, she describes the various instruments (Schwartz Value Survey; the Life Orientation Questionnaire; and the Organisational Culture Profile) used to sample individual and work-related behaviours. Qualitatively, she elaborates on the triangulation and interpretative methods used to analyse and interoperate the qualitative data obtained from the interviews. This chapter is highly technical and provides an excellent overview of the utilised research strategy used to obtain the results used in the following chapters.

Chapters 6 and 7 focus on the presentation and interpretation of the author's results. These chapters provide a glimpse into the lives, psyches and daily realities of managers within South Africa. The results present interesting findings relating to managerial identity and overall well-being. It would seem, although not explicitly reported by the author, that managerial identity is context bound and is influenced by the individual's perception of self and their ability to cope with the work-related demands. Her results also indicate that there is still cultural sensitivity, yet cultural segregation, within the South African business environment. This is similar to the findings and interpretations presented by Cilliers and Coetzee (2003) as well as Cilliers and Kossuth (2002) in different South African contexts. Her results also indicate that affirmative action and BEE place extreme pressures on managers and on the financial wellness of the organisation. Further, the results indicate that organisational culture may have an impact on an individual's ability to manage transcultural conflicts as well as impact on their general health. The author presents various theoretical and interpretative models relating to sense of coherence and managerial functioning. Although these models aren't empirically validated, they do prove relevant to the South African business environment.
The final chapter is centred on the interpretation of the results and presenting various recommendations for future research. Although this review cannot do justice to all the findings, the author presents an interesting case for transcultural management. Her results (and models) emphasise the importance of relationships, fairness, equality and transparency in transcultural management. She argues that healthy organisations should focus on building an organisational culture that presents equal opportunities, is supportive, changes or challenges gender structures, develops active conflict management culture and has discipline. Similarly, the author presents useful mini-intervention-like strategies to aid in the development of high-sense-of-coherence managers. She suggests that interventions be focused on both an organisational and individual level, to ensure and sustain the well-being of managers. This argument has also been suggested and validated by various other South African authors (see Jorgensen, 2009; Spangenberg \& Orpen-Lyall, 2008; Van Zyl \& Rothmann, 2012).

To conclude, this book provides the reader with an interesting read and suggests various strategies that can be utilised by the specialist practitioner to develop healthy organisations through focusing on the development of high-sense-ofcoherence managers. Her results build upon the work of Professor Deo Strümpher regarding psychofortology and salutogenetics within the South African context and are a welcome edition to South African literature. This book is an excellent companion for specialist practitioners, researchers and academics working within the field of salutogenesis. However, the layman practitioner might find little use for it in his or her daily practice.

\section{References}

Antonovsky, A. (1987). Unravelling the mystery of health - how people manage stress and stay well. San Francisco, CA: Jossey-Bass Publishers.

Cilliers, F., \& Coetzee, S.C. (2003). The theoretical-empirical fit between three psychological wellness constructs: Sense of coherence, learned resourcefulness and self-actualisation. South African Journal of Labour Relations 27(1), 4-24.

Cilliers, F., \& Kossuth, S.P. (2002). The relationship between organisational climate and salutogenic functioning. South African Journal of Industrial Psychology 28(1), 8-13.

Jorgensen, L.I. (2006). Work-related well-being among police members on the NorthWest Province. Unpublished doctoral thesis, North-West University, Potchefstroom, South Africa.

Spangenberg, J., \& Orpen-Lyall, M. (2008). Stress and coping strategies in a sample of South African managers involved in post-graduate managerial studies. SA Journal of Industrial Psychology, 26(1), 6-10.

Van Zyl, L.E., \& Rothmann, S. (2012). Beyond smiling: The development and evaluation of a positive psychological intervention aimed at student happiness. Journal of Psychology in Africa, 22(3), 104-119. 